\title{
Experiências de Perda e de Luto em Escolares de 13 a 18 Anos
}

\author{
Basílio Domingos ${ }^{2}$ \\ Universidade de São Paulo \\ Maria Regina Maluf \\ Universidade de São Paulo/ Pontifícia Universidade Católica de São Paulo
}

\begin{abstract}
Resumo
O estudo examina experiências de perda e luto de 25 escolares de 13 a 18 anos sobreviventes de perdas de entes queridos por morte. Como método foi utilizada a entrevista semi-estruturada. Através da análise de conteúdo foram construídas cinco grandes categorias: circunstâncias das perdas, reações às perdas, o adolescente enlutado e a família, o adolescente enlutado e a escola, o adolescente enlutado e expressão emocional. As perdas resultantes de homicídio, suicídio e AIDS, foram as mais difíceis de serem expressas e compartilhadas, pois além de se constituírem em situações problemáticas e mobilizadoras de fortes conteúdos emocionais, são crivadas de juízos de valor e objeto de estigmas socialmente construídos. Para muitos pesquisados, a família e a escola foram percebidos como ineficazes em termos de fonte de suporte para suas necessidades resultantes do luto.
\end{abstract} Palavras-chave: Morte e luto; adolescente e luto; luto na família; luto na escola; expressão emocional.

Experiences of Loss and Mourning among School-Children Aged 13 to 18

Abstract

This study examines the experiences of loss and mourning among 25 school-children aged 13 to 18 who suffered expressive losses through death. Methodology was based on a semi-structured interview. Five categories emerged from content analysis: circumstances of loss, reactions to loss, the mourning adolescent and family, the mourning adolescent and school, the mourning adolescent and his/her emotional expression. Adolescents showed greater difficulty in expressing and sharing losses which were a result of homicide, suicide and AIDS. Not only are such losses a consequence of problematic situations triggering strong emotional contents, they are also worsened by the fact that they are often the object of prejudice and socially constructed. Many interviewed subjects consider family and school ineffective as a source of support for their needs resulting from mourning. Keywords: Death and mourning; adolescent and mourning; mourning in the family; mourning at school; emotional expression.

Ainda que a finitude seja inerente à vida, o homem ocidental a tem como uma de suas maiores preocupações. Assim, aceitar a morte do outro freqüentemente tem sido problemático. Como afirma Bowlby (1993), a perda pode se tornar uma provação, tanto para quem a enfrenta como para os circunstantes, que muitas vezes não sabem o que fazer para consolar uma pessoa enlutada. O luto, entendido como uma constelação de reações psíquicas, conscientes e inconscientes, a uma perda significativa, é uma experiência complexa que transcende o âmbito individual. É, segundo Rowling (1995, p. 37), uma experiência "moldada por nosso passado, nosso presente e nossas esperanças no futuro, conceitualizados em nossos pensamentos e expressos na linguagem e comportamento. É também uma experiência que é moldada pelo contexto social em que ele ocorre". O luto é igualmente uma crise que atinge o indivíduo, sua família e os sistemas mais amplos da sociedade dos quais

Endereço para correspondência: Rua Aimberé, 944, 304, 05018 011, São Paulo, SP. Fone: (11) 36752901. E-mail:b_domingos@hotmail.com ${ }^{2}$ Esta pesquisa é parte da dissertação de mestrado do primeiro autor e foi financiada pela FAPESP participa (Bromberg, 1994). Portanto, o comportamento desses sistemas de algum modo interfere no enfrentamento à crise do luto pelo indivíduo, na medida em que a forma em que estes respondem ao indivíduo enlutado pode se traduzir em suporte ou não à sua condição de enlutado.

\section{O Adolescente, a Morte e o Luto}

É capaz, o adolescente, de manifestar o luto? Bowlby (1982, 1993), conhecido por articular os pressupostos da etologia e da psicanálise em sua teoria do vínculo, afirma que o adolescente, assim como a criança, manifesta o luto como resposta à quebra de um vínculo afetivo. Para este autor, o vínculo tem um valor de sobrevivência, de sorte que a perda da figura de vínculo é percebida como desamparo, podendo desencadear uma forte ansiedade de separação e inclusive o pânico.

Convém lembrar que a psicanálise, através do trabalho com crianças, mostrou que estas sofrem o luto, e mesmo que ainda não consigam verbalizar, em razão de seu nível de desenvolvimento cognitivo, já são capazes de perceber o que acontece à sua volta, inclusive a morte. Esta percepcão pode mostrar-se simbolicamente através de atividades 
expressivas como o jogo e o desenho (Aberastury, 1984) Entretanto, é somente a partir do período das operações formais que a criança pode compreender a morte, enquanto fenômeno irreversível, universal e inevitável (Kane, 1979; Koocher, 1973; Nagy, 1948; Torres, 1979). Todavia, na formação desse conceito, deve-se considerar também a experiência da criança com a morte (Bluebond-Langner, 1977)

Do ponto de vista do desenvolvimento, a relação do adolescente com a morte e suas reações à perda de um ente querido são peculiares, especialmente porque são moduladas pela fase de desenvolvimento em que ele se encontra, no processo do qual, segundo Erikson (1971), a construção da identidade é a tarefa central. Entretanto, Kastenbaum e Ainsenberg (1983) alertam para o fato de que a aquisição da individualidade pode, nas primeiras fases da adolescência, evocar a percepção de si mesmo como um ser solitário, fazendo com que o jovem sinta-se mais vulnerável à morte, tanto própria quanto de alguém significativo. Também contribui para esse sentimento, o ônus resultante das tarefas de desenvolvimento que se impõem na adolescência, tai como a superação emocional, domínio, intimidade e ambivalência em relação aos pais (De Mico, 1995). Some-se a isso as perdas enfrentadas pelo adolescente, das quais se destacam as perdas do corpo infantil associadas às transformações corporais e fisiológicas correspondentes, a perda dos pais da infância e da identidade e do papel infantil descritos por Aberastury e Knobel (1981). Efetivamente, o confronto com morte na adolescência pode exaurir as limitadas estruturas defensivas inerentes a essa fase de desenvolvimento, precipitando respostas radicais (Kastenbaum, 1986).

Entre os fatores que influenciam o luto dos adolescentes e crianças, destacam-se o conhecimento que eles têm das causas e circunstâncias da perda, especialmente o que lhes é dito sobre a perda e as oportunidades que têm de compartilhá-la, os padrões de relacionamento familiar anterior e a mudança desses padrões e reestruturações do sistema familiar em conseqüência da perda, nos casos em que o objeto da perda é um dos pais (Bowlby, 1993).

Certamente a perda de um dos pais na adolescência pode comprometer o processo de aquisição da independência e da autonomia adulta pelo jovem. Entretanto, a morte de um colega, de um amigo íntimo, pelo fato deste ocupar um lugar importante na vida do adolescente, podendo até suprir necessidades de ordem social e emocional negligenciadas pela família (Skalar \& Hartley, 1990), pode ser igualmente desestruturante, principalmente porque perdas de pessoas próximas e parecidas com ele mesmo têm a força de o alertar vigorosamente sobre sua vulnerabilidade e mortalidade, na medida em que sua fantasia de imortalidade é questionada, especialmente se essas perdas são repentinas, como ocorre por exemplo em casos de suicídio e homicídio (Gordon, 1986; Schacter, 1991/1992). Segundo Parkes (1993), esse tipo de perdas, notadamente as resultantes de homicídios, freqüentemente induzem nos sobreviventes uma ansiedade intensa, podendo estar presente uma sintomatologia condizente com quadro de Distúrbio de Stress Pós-traumático (segundo a definição do DSM-III-R, APA, 1989). Além disso, podem advir sentimentos de vitimização, culpa, autoreprovação, raiva e vingança em relação aos presumíveis culpados pela perda. Adicione-se a isso a descrença e questionamento da justiça social (Parkes, 1993) e de Deus (Parkes, 1998).

No rol das perdas dramáticas têm-se também as mortes por suicídio e AIDS. Freqüentemente esse tipo de perda instiga a desaprovação social ou não atrai a atenção das pessoas, por resultarem de causas obscuras ou fortemente estigmatizadas. Perdas desta natureza tendem a ser socialmente "não autorizadas", levando igualmente a "lutos não autorizados", ou seja, a situações em que o luto 'não pode ser publicamente reconhecido, pranteado ou beneficiário de suporte social' (Doka, 1989, citado em Corr 1998/1999, p. 2).

Finalmente, é importante enfatizar que qualquer perda é acompanhada por uma constelação de perdas secundárias, isto é, subseqüentes à perda inicial. Nesse caso, emergem privações de natureza física e/ou psicossocial, impostas à pessoa enlutada, uma vez que deixam de existir as gratificações anteriormente providenciadas pelo morto, no desempenho de seus múltiplos papéis. Cada uma dessas privações (entendidas como perdas) impõe seu próprio luto, sendo que ocasionalmente é mais difícil lidar com esses lutos do que com o luto referente à perda do ente querido (Rando, 1993).

\section{Luto e sua Expressão}

Restrições sobre a manifestação aberta de afetos relacionados à perda remontam ao século XIX e seus resquícios ainda perduram até nossos dias, como uma das características da civilização ocidental cada vez mais secularizada, menos ritualizada (ao menos em termos formais) e tendente a negar a morte. Conseqüentemente tende a rejeitar e suprimir o luto, visto como indigno, vergonhoso e sinônimo de fraqueza de caráter, prestandose apenas para exacerbar desnecessariamente a dor (Ariès, 1977, 1982). Trabalhos de terapia do luto têm mostrado que essa atitude não auxilia a elaboração do mesmo, uma vez que inibir sentimentos e emoções genuínos a favor da expectativa social pode gerar sentimentos de culpa e de inadequação (Fleming \& Adolf, 1986), conteúdos esses passíveis de serem expressos pelos adolescentes, a título compensatório, através de outros canais, como agressividade, 
desafio a figuras de autoridade, uso e abuso de drogas (Raphael, 1983, citado em Fleming \& Adolf, 1986). Se algum desses comportamentos for tomado para evitar a dor, o processo de luto pode ser truncado, uma vez que vivenciar a dor é uma condição indispensável para o início do processo de luto (Rando, 1993). Quando isto não ocorre, o luto pode complicar-se ou mesmo tornar-se patológico (Bowlby, 1982, 1993; Bromberg, 1994; Fleming \& Adolf, 1986; Pincus, 1989; Rando, 1993). Entretanto, formulações recentes têm relativizado essa assunção, pontuando que enfrentar a perda pode ser útil para alguns enlutados, sendo que, para outros, a não confrontação e mesmo a evitação podem ser a melhor forma de lidar com a perda (Stroebe, 1992/1993).

Ainda carentes de maior clareza, em virtude da multiplicidade de termos e critérios quanto à sua classificação, as formulações atuais tendem a identificar o luto patológico com a intensificação, inibição, adiamento ou prolongamento das respostas decorrentes do luto em si (Middleton, Raphael, Martinek \& Misso, 1993). Para Rando (1993), que opta pelo termo luto complicado ao invés de luto patológico, dois aspectos se destacam no luto complicado: 1) O indivíduo nega, reprime ou evita aspectos da perda ou 2) resiste em se desligar do falecido. Ainda para a autora citada, o luto complicado pode desencadear: a) sintomas (psicológicos, comportamentais, sociais e físicos) de luto complicado, b) sintomas específicos de luto complicado (ausência de pesar, luto adiado, luto inibido, luto distorcido, luto não antecipado e luto crônico), c) perturbações mentais ou físicas, d) morte.

O luto só é resolvido quando a pessoa perdida não é esquecida, mas sim internalizada e tornada parte da pessoa que sofreu a perda (Pincus, 1989). Na verdade, trata-se de um processo geralmente longo e trabalhoso, de transição psicossocial (entenda-se aquisição de uma nova identidade), no qual um conjunto de concepções sobre o mundo, cuja validade era aferida pela presença da pessoa falecida, não fazem mais sentido e, portanto, devem ser atualizadas para se adequarem à nova realidade (Parkes, 1998).

Considerando que a adolescência é um fator de risco para o luto, verifica-se que, à semelhança do que acontece na sociedade, a família não tem desempenhado a contento o papel de fonte de suporte para o adolescente enlutado (Bromberg, 1994; Gordon \& Klass, 1979, citados em McNeil, 1986; Harris, 1991). O mesmo se pode dizer da escola, particularmente dos professores, que podem ser surpreendidos por situações de morte e luto com as quais não estão preparados para lidar, nem prática e nem emocionalmente (Mahon, Goldberg \& Washington, 1999; Pincus, 1989; Rowling, 1995).

Nesta pesquisa temos como objetivo examinar as experiências de perda e de luto vivenciadas por um grupo de escolares sobreviventes de perdas de entes queridos por morte. Consideramos também como, na percepção desses escolares, comportaram-se a família e a comunidade escolar, quando das perdas em questão.

\section{Método}

\section{Participantes}

A pesquisa foi realizada em duas escolas públicas da região metropolitana de São Paulo. Os alunos foram convidados a participar da pesquisa através de uma exposição coletiva dos objetivos, sendo que o pesquisador se dispôs a conversar individualmente com todos os que manifestassem interesse nessa participação. Foi garantido o anonimato e o consentimento informado de todos os participantes. Foi também previsto um serviço de apoio e aconselhamento para eventual encaminhamento daqueles que, em decorrência da pesquisa ou não, apresentassem necessidade de ajuda

Com base nesses procedimentos, o grupo de participantes voluntários ficou constituído por 25 adolescentes, de 13 a 18 anos, sendo 18 do sexo feminino e 7 do sexo masculino, provenientes de diferentes séries do ensino fundamental e médio.

\section{Procedimentos}

Inicialmente o pesquisador colheu dados demográficos sobre o adolescente e suas condições de vida, bem como informações iniciais sobre as circunstâncias em que ocorreram as perdas mencionadas pelo participante, utilizando uma ficha de registro. Em seguida foi realizada uma entrevista de tipo clínico, seguindo um roteiro que garantia a cobertura dos seguintes tópicos: circunstâncias da perda; como era o relacionamento com a pessoa falecida; reações à perda; impacto da perda nas atividades escolares e rotineiras e no relacionamento com outrem; a família como suporte/outras redes de apoio; a comunidade escolar como suporte.

Foi feita também uma segunda entrevista, para aprofundamento dos temas abordados no primeiro encontro. Essa fase teve como objetivo propiciar ao entrevistado e ao pesquisador a oportunidade de retomar tópicos que, por alguma razão, não tivessem sido tratados anteriormente. Foi também o momento de se dar um fechamento à relação estabelecida, a qual, pelo teor do assunto abordado, poderia eventualmente ter mobilizado conteúdos de caráter emocional dos entrevistados.

\section{Análise dos Dados}

Para análise das entrevistas utilizamos o referencial da análise de conteúdo (Bardin, 1977), o que nos permitiu a construção de categorias temáticas. Foram construídas cinco categorias, a saber: circunstâncias das perdas (relacionamento 
com o falecido e informações sobre a perda); reações às perdas (reações dos adolescentes às perdas, sistematizadas em reações iniciais, reações a perdas repentinas, reações a perdas esperadas e outras reações); o adolescente enlutado e a família (vivências do adolescente enlutado na família e o comportamento da família em relação a ele, bem como as mudanças nesse sistema em função da perda e do luto); adolescente enlutado e a escola (vivências do adolescente enlutado na escola: o impacto do luto nas atividades escolares, o relacionamento com a comunidade escolar e o comportamento dessa comunidade em resposta ao adolescente enlutado); o adolescente enlutado e expressão emocional (fatores que, na percepção dos adolescentes, dificultam a expressão emocional de seu luto).

\section{Resultados}

Foram relatadas 38 perdas, sendo que 10 são de avós, nove de pai, sete de amigos e as restantes 12 concernem pessoas com diferentes graus de parentesco.

Dezesseis dessas perdas relatadas ocorreram até 2 anos antes do período da pesquisa, 11 entre 3 e 4 anos, 6 entre 5 e 8 anos, duas acima de 8 anos. Sobre as 3 restantes não houve informação.

Quando das perdas, um adolescente tinha 6 anos de idade, 14 entre 7 e 11 anos, 10 entre 10 e 14 anos, 8 entre 15 e 18 anos e sobre cinco perdas não houve informação sobre a idade em que ocorreram

Quanto às causas das perdas, verificou-se que 31 foram repentinas, sendo que 21 ocorreram por causas externas (11 acidentes de trânsito, seis homicídios, três perdas por afogamento ou queda, um suicídio) e 10 resultaram de diversos problemas de saúde. As outras sete foram perdas esperadas, porque ocorreram em conseqüência de doença prolongada.

Os jovens que participaram da pesquisa são provenientes de famílias de baixa renda, residentes na periferia urbana carente de infraestrutura e serviços básicos. Vinte desses jovens são oriundos de famílias monoparentais, sendo que em 19 casos a figura ausente é a paterna e em um caso a mãe é a ausente. Essas ausências devem-se a: separação (14, sendo que cinco pais faleceram nessa condição de separados) e falecimento (seis). Para 15 dos adolescentes a ausência do pai aconteceu nos primeiros 7 anos de vida e para os outros 5 ocorreu após os 7 anos.

\section{Circunstâncias das Perdas}

Examinamos a qualidade do vínculo estabelecido com o morto, a participação nos acontecimentos da perda, especialmente as circunstâncias em que os pesquisados tiveram conhecimento da perda e as causas que provocaram a morte. Este último aspecto será abordado na categoria referente às reações às perdas.

Relacionamento com o falecido: Excetuando 5 adolescentes (um dos quais sem informação) que mencionaram que os vínculos estabelecidos com as pessoas falecidas eram pouco afetivos ou mesmo inexistentes, para outros 20 esses vínculos eram fortes. A qualidade e o significado dos vínculos ficam sugeridos, quando esses adolescentes se referem a essas pessoas usando atributos como protetor, confidente, orientador, muito chegado, muito presente, companheiro. Além disso, ao se referirem a como reagiram à perda, afirmaram que se sentiram sós e desesperados com o rompimento desses vínculos:

eu chorei muito... queria ir junto; foi uma grande perda; era a única pessoa que eu tinha; eu gostava muito dele... eu não queria que ele morresse por nada... uma vez eu pensei que se ele morresse eu iria junto

me abalei demais, porque era o único amigo, o único irmão, o único assim tudo que eu passava ele passava, então eu só tinha ele, eu não tinha mais ninguém, porque meus pais estão separados e meu padrasto não gosta muito da gente né, o meu pai ele não liga pra gente mesmo desde pequininho, desde quando nasci não liga ... então eu me abalei assim muito e queria ir junto com ele, queria que tivesse sido comigo do que com ele né, porque foi demais (menina, 18 anos, perdeu irmão por afogamento).

Informação sobre a perda: Em relação à tomada de conhecimento, 14 adolescentes foram informados e viveram os acontecimentos da perda no momento em que ela ocorreu. Entretanto, para 11 adolescentes isso não ocorreu: 5 adolescentes souberam da perda tardiamente (atraso de 2 dias, 1 semana, 1 mês, 4 meses e 18 meses) e nos outros seis casos, a família tentou ocultar o ocorrido, provavelmente para proteger as crianças da tragédia. Este artifício resultou em benefícios questionáveis, pois longe de ajudar, deixou a maioria desses adolescentes mais ansiosa, como se depreende do depoimento de uma menina que perdeu o pai na infância por acidente.

$\mathrm{Na}$ época eu não fiquei sabendo assim, logo de cara, a minha mãe enrolava e falava que ele tinha ido viajar e que estava bem. Mas eu via que ela não estava bem, porque ela ficou muito mal, ficou de cama e internada. Aí ela pegou e falou que ia na casa de minha tia e fez o enterro. Foi no enterro e eu e minha irmã não ficamos sabendo deste enterro. Até hoje eu fico muito chateada por isso... Ela escondeu da gente ... e ela nunca, nunca falou. Eu não sei o porquê que ela nunca falou, né?

C. (17 anos), que perdeu um primo por suicídio, mostrase muito angustiada diante da ocorrência. Na busca infrutífera 
do motivo da tragédia, sua angústia foi intensificando-se diante de informações desencontradas, rumores sobre o envolvimento de um tio com o mundo das drogas e do silêncio e desconforto de pessoas da família em falar a respeito do ocorrido.

O ano passado chamei o meu irmão R., qual foi o motivo do meu primo ter-se matado?... eu falei chorando, implorei qual foi o motivo de meu primo ter-se matado? Ainda saiu chamando-me de boba...Ré, você vai ficar com isso na cabeça? Até agora, hoje, não entendi qual foi o motivo do meu primo ter-se matado ... que será que aconteceu com ele, que eu não sei qual é a verdade, eu não sei quem está a falar a verdade, se é a minha família se é a família dele; que até hoje não entendi. Eu não sei qual é o lado dessa história. Uns falam ... mexia com drogas, outros falam que era uma intriga com esposa do meu tio... não sei bem explicar ao senhor o que aconteceu ... Depois daquele dia que levei uma bronca nunca mais perguntei mais nada a ninguém. É o medo.

\section{Reações às Perdas}

Reações iniciais: Ao confrontar-se com a notícia da perda, a reação imediata de 16 adolescentes (14 sobreviventes de perdas repentinas e dois por perdas esperadas) dos 25 pesquisados foi choque, descrença, susto ou desespero, explicitadas por expressões como: não podia acreditar, senti um baque, fiquei desesperado, não sabia o que fazer, fiquei congelado na hora, veio aquele choque.

Embora a maioria dos participantes tivesse reagido à perda de forma intensa ou mesmo desesperada, seis adolescentes não tiveram essa reação. Tendo sofrido perdas na infância, revelaram que só tardiamente, na adolescência, deram-se conta de quanto essas perdas foram importantes. Para três deles, isso aconteceu porque eram ainda muito pequeninos quando as perdas ocorreram e, outros três alegaram a falta de convivência com a pessoa perdida. D. (15 anos), uma dessas adolescentes, que na infância perdeu um avô com o qual vivia numa relação paternal, afirmou que na ocasião se confundiu em seus sentimentos: era muito pequena, não sabia se ria, se eu chorava, fiquei meio estranha, afirma. Já S. (16 anos), que perdeu o pai aos 6 anos e o avô aos 16, só tardiamente ficou enlutada pelo pai, ao manusear fotografias pertencentes a este, tendo ficado muito abalada. Os outros três adolescentes não fizeram referência às suas reações iniciais.

Reações a perdas repentinas: Nessas perdas, no geral, os depoimentos indicam respostas de tristeza, ressentimento, dor, autocomiseração, desespero, resignação, desorientação e, particularmente, culpa pela impotência de não ter podido evitar a morte, bem como raiva e revolta contra o destino visto como injusto pela perda prematura e cruel do ente querido. Patentes em 16 adolescentes (seis sobreviventes de homicídios, três de perdas por problemas cardiovasculares e outras complicações médicas e sete de acidentes, viários ou queda), esses conteúdos, em particular raiva e desejo de vingança dirigidos a presumíveis responsáveis pela tragédia, foram explicitados com ênfase por sobreviventes de perdas por homicídio. Eles também questionaram e clamaram pela justiça social e de Deus e, a despeito do tempo transcorrido entre a ocorrência da tragédia e o momento da pesquisa, de forma vívida ainda se sentiam vitimizados, revoltados, injustiçados e inconformados.

...fiquei revoltada da vida porque meu pai tinha tudo pra viver, 47 anos, novo pra caramba e tiraram a vida dele... nossa, se tivesse morrido mesmo porque estava na hora, mais ou menos ... A gente fica mal por dentro quando não sabe o que pensar ... se eu pudesse chegar nessa pessoa...(o assassino) veria o que faria na hora ... nossa, fiquei super mal, fiquei acabada por dentro. Nada justifica uma pessoa tirar a vida de outra, é horrível. (menina, 17 anos, perdeu o pai assassinado)

Especialmente nos casos em foco, e, a avaliar pela forte tonicidade emocional dos depoimentos, as perdas foram vivenciadas (ou estavam sendo vivenciadas) com muita intensidade. Nos outros casos, os alvos foram o destino, os que supostamente negligenciaram o socorro ao falecido ou à família e os colegas vistos como insensíveis ao sofrimento dos jovens enlutados.

Entre os adolescentes citados, também registramos uma variedade de alterações transitórias que vão desde insônia, falta de apetite ou compulsão com relação à ingestão de comida, náuseas, dores no peito, tremedeira, febre, flacidez, e processos infecciosos. Três desses adolescentes queixaram-se igualmente de pensamentos e imagens recorrentes referentes à pessoa falecida.

Ansiedade e medo da morte e do morrer despontaram de relatos de 13 adolescentes sobreviventes a perdas repentinas. Esses conteúdos referem-se à própria morte e a de entes queridos e à possibilidade de avistar cadáveres ou espíritos de pessoas falecidas. Para três desses jovens, a morte temida é a morte violenta, com dor, isto é, por assassinato.

...eu tenho medo de morrer, ai se eu morrer, eu quero mesmo a morte normal eu não quero facada, eu não quero tiro, não quero nada, quero morte normal, de velhice, não sei ... quem manda é Deus, né ... Ah! Sei lá ... tenho um medo danado, lascado, de deixar tudo para trás. (menina, 17 anos, perdeu o pai assassinado)

A ansiedade e medo da morte e do morrer também se manifestaram no depoimento da jovem que sofreu perda 
por suicídio: à angústia de não ter a resposta acerca do motivo que levara o primo a se matar, juntou-se o medo de que sua mãe viesse a morrer.

Mostrando uma atitude desafiadora e de curiosidade, quatro dos 13 adolescentes citados, ao invés de temer a morte e o morrer se sentiram instigados a buscar explicações sobre esses fenômenos, sendo que dois parecem vangloriar-se de ter chegado a uma opinião própria a respeito desse assunto. Essas opiniões referem-se a uma maior consciência sobre a própria finitude e ao fato de a morte ser um evento universal e imprevisível, realidade que, supostamente, levou esses jovens a superarem o medo de morrer, valorizarem a vida e aproveitar o que ela oferece de bom.

Antes eu tinha medo da morte, agora não tenho mais, acho que se tiver que acontecer acontece em qualquer lugar. Minha mãe fala muito assim: você não pode sair que pode acontecer isso... mas eu falo, mãe, se eu tiver que morre eu vou morrer na rua ou a casa vai desabar em cima de mim. Então que se você tiver que morrer vai morrer de qualquer jeito. Antes eu não me ligava muito nisso. Depois que aconteceu tudo isso (mortes do tio e do avô) eu comecei a pensar. Eu parava e pensava ué, como pode, as coisas acontecerem de uma hora para outra, não tem começo nem final. Então eu comecei a perguntar, eu hoje pergunto muitas coisas, sou muito curiosa; pergunto pros outros.. aí eu formei a minha própria opinião, entendeu? (menina, 13 anos)

Reacões a perdas esperadas: As perdas esperadas foram sete e relatadas por quatro adolescentes. Porque previsíveis, essas perdas, no geral, foram recebidas por esses adolescentes com certa tranqüilidade, ainda que tenham, assim mesmo, causado muita dor. Foi super normal, disse uma entrevistada. Todavia, dois desses adolescentes não deixaram de se surpreender com a perd e os restantes dois afirmaram que se sentiram impotentes e frustrados diante da deterioração física e ausência de seus parentes internados e, em face dessa situação, tenderam a reagir com raiva, isolamento e atitudes agressivas com colegas.

Outras reações: O passar do tempo sem a pessoa querida traz inevitavelmente a vivência da falta e a saudade. Esses conteúdos foram explicitados por 19 dos 25 adolescentes pesquisados, relacionando-os a ausência de apoio, carinho, de convívio diário, necessidades essas anteriormente supridas pela pessoa falecida. Alguns desses adolescentes disseram que esses conteúdos, geralmente acompanhados de tristeza, são reativados ou tornam-se mais intensos em datas de aniversários e em situações que lembram a pessoa perdida. Sentir-se fragilizado por alguma contrariedade também evocou esses sentimentos.

No dia da morte foi difícil pra gente; no dia do aniversário dele foi difícil também. Porque ele gostava de sentir, ver a família reunida... não sei explicar... A gente tenta no Natal... a gente chora, todo mundo, porque a gente queria que ele tivesse lá, porque ele gostava muito de festa... é normal a gente lembrar... a gente relembra, né... É difícil também porque a gente lembra que ele está, estava sempre nas festas e agora não está mais... falta alguém mais... é difícil... mas a gente vai levando... (menina, 15 anos).

Verificamos também que esses afetos estavam sendo vivenciados intensamente por sete adolescentes cujas histórias de vida se destacam pela ausência do pai na tenra idade em virtude da separação e pela ausência desse mesmo pai em virtude de falecimento.

E o meu pai foi assim, a minha mãe era casada com ele e separou quando eu tinha 3 anos e dos 3 anos aos $14 \mathrm{eu}$ nem sabia as características dele e foi quando a adolescência começou e eu queria conhecer meu pai e tudo e conheci aos 14 anos num sábado. Quando foi na outra seounda da outra semana aí veio o recado de que ele tinha falecido, então pra mim chocou um pouco porque desde os 3 anos eu querendo conhecer o pai; e assim, conheci num dia, não tive nem oportunidade de falar, nem de chamar pai né, ter um diálogo com ele e tudo né, e assim, perdi ele de uma hora pra outra. (menina, 18 anos)

Diferentemente da tendência manifesta pela maioria dos adolescentes da pesquisa, que reagiram pronta e intensamente à perda logo após seu conhecimento, seis deles, tendo sofrido a perda na infância, só tardiamente, na adolescência, deram-se conta do quanto essas perdas foram importantes. Para três desses jovens isso se deveu à falta de convivência com a pessoa falecida e os restantes três disseram que tinham pouca idade quando as perdas ocorreram: Era muito pequena, não sabia se ria, se eu chorava, fiquei muito estranha, expressou-se D. (15 anos).

Para três adolescentes, as vivências que tiveram foram premonitórias do que viria a ocorrer. N. previra em sonhos o acidente que vitimara o namorado e se sentia culpada por não ter alertado a vítima; L. viu lâmpadas da casa se apagarem e acenderem-se por várias vezes e já $C$. assegurou ter enxergado um vulto de um rosto na janela do apartamento onde mora e, dias depois, soube do suicídio do primo que pulara da janela.

\section{$O$ adolescente enlutado e a família}

A perda e o luto alteraram de diferentes maneiras o sistema familiar. Para nove dos adolescentes, a perda 
desencadeou, acirrou, desvelou conflitos de relacionamento familiar ou trouxe dificuldades econômicas nos casos em que o falecido era o único provedor da familia:

Eu mais acusava minha mãe, falava que se eu não tinha pai a culpa era dela, porque ela não foi capaz de me dar un pai, falava pra ela, porque ela não ficou com o meu pai (menina, 16 anos perdeu o pai e um avô por doença)

Três dos adolescentes referidos tiveram que mudar de casa e se integrar em outros agregados familiares, aos quais até o momento da pesquisa ainda não tinham se adaptado, como por exemplo se vê no depoimento a seguir:

...tem muita família vivendo numa casa só, entendeu? A mesma família, só que diferente. Uma parte é João da Cunha (referência a nome de família) outra é Baltazar (referência a nome de família), lota, assim dá um atrito lá dentro de casa às vezes, não sei, acho que seria normal, mas é muito difícil uma casa que tenha várias famílias numa só e ser tudo normal. (menino, 15 anos, perdeu a mãe por problema cardíaco)

Em cinco casos os adolescentes sentiram-se preocupados com o luto dos parentes, a ponto de minimizar o próprio pesar, como por exemplo:

...fiquei chateada, é lógico, muito chateada, mas eu sent muita dor, muita pena do meu avô. Acho que tudo o que eu pensava naquela hora era o meu vô; meu Deus, como ele vai fazer, então eu senti mais assim, senti muita pena dele, e me senti sozinha também naquele momento. (menina, 13 anos)

O comportamento da família como suporte foi percebido pela maioria dos adolescentes como pouco eficaz. Dezesseis dos adolescentes da pesquisa, embora reconhecessem ter recebido algum suporte da família, ressalvaram que esse apoio poderia ter sido melhor caso o ambiente familiar fosse mais acolhedor e tolerante ao seu luto, encorajasse a expressão de afetos e se eles, os adolescentes, não tivessem que se preocupar também com o luto dos parentes em detrimento de suas necessidades. Em virtude desses problemas, oito desses jovens relataram, tristes, que não puderam contar com o apoio da família.

Tem várias vezes que tento falar alguma coisa em casa conversar. Com a minha mãe, meu padrasto às vezes est

lá. Aí eu começo a falar e eles não dão muita importância e aí, eu já nem ligo. (menina, 18 anos, perdeu o pai e uma avó por doença)

\section{O Adolescente Enlutado e a Escola}

Impacto nas atividades escolares: 16 dos 25 adolescentes mencionaram dificuldades de retomar e acompanhar as atividades escolares e manter o desempenho de antes da perda durante o primeiro ano subseqüente à perda. Desses, 13 referiram-se a problemas de atenção e concentração como o sintoma mais marcante. Esses problemas foram relacionados pelos próprios entrevistados como estados de ansiedade, intrusão de pensamentos recorrentes sobre a perda e a pessoa falecida, fadiga, sonolência, tontura e crise de choro. Em virtude disso, um adolescente afirmou ter sido reprovado uma vez na quarta série e três na sexta.

Eu tava na terceira série, aí eu passei pra quarta, aí eu comecei a ter nota baixa, comecei... aí eu repeti a quarta série, uma vez só, aí eu passei pra quinta com isso na cabeça ainda, cheguei na sexta e repeti mais 3 anos a sexta série, a depois, começou a me dar canseira aí... Ah, eu não tirava essa idéia da cabeça, vixe, quando tinha provas, eu não estudava, só pensando ... (menino, 17 anos, que perdeu o pai por ataque cardíaco)

Entretanto seis outros adolescentes disseram que a perda não prejudicou suas atividades escolares, afirmando terem sabido administrar seus pesares.

Não, não foi assim muito fácil assim né,... acho que não interferiu em nada porque a gente põe os estudos em primeiro, então eu procurava deixar de lado, não pensar, pelo menos naquela hora, porque eu sabia que estava ocupada estudando. (menina, 14 anos, perdeu o primo em acidente de trânsito e posteriormente o avô por câncer)

Comportamento da comunidade escolar em relação ao aluno enlutado: 16 adolescentes da pesquisa reconheceram ter recebido de professores e colegas algum tipo de apoio prático, ou encorajamento pautado no senso comum (não fique assim, seja forte, também jápassei por isso, isso vai passar). Alguns professores adiaram ou prorrogaram avaliações, colegas explicaram ou ajudaram a realizar trabalhos escolares. Como fonte de suporte os colegas são citados 14 vezes e os professores, nove.

É difícil no começo acho que foi no $2^{\circ}$ semestre. Teve matéria que eu quase fiquei sem nota. Não aconteceu porque eu tinha amigos que me ajudaram com as notas $\mathrm{d} a$ escola e eles (os colegas) me ajudaram a fazer as notas que eu precisava...Trabalhos... essas coisas assim... e quando tinha data que eu não conseguia fazer ou entregar um trabalho, eles (os professores) adiavam a data, marcavam outra data, conversavam comigo ... (menina, 15 anos, perdeu um irmão assassinado) 
Esses mesmos jovens também fazem referência à indiferença da comunidade escolar com relação aos seus dramas. Tal atitude, segundo eles, deixou-os sem ajuda emocional e não os animou a solicitá-la. Por outro lado, muitos deles admitiram sua dificuldade em se auto-revelar, sendo este um dos tópicos que abordaremos na categoria a seguir (Luto e Expressão Emocional).

Relacionamento com os colegas: Nove adolescentes tiveram dificuldades de se integrar nos grupos de amigos, interagir com colegas e manter os relacionamentos habituais, devido às constantes variações de humor, apatia e tendência a desgostar as pessoas, expressando sua raiva indiscriminadamente. As vezes eu fico nervosa e eu desconto em alguém que não tem nada a ver, disse uma menina, ainda sob o efeito do luto.

Essa forma de se comportar afastou os colegas, deixando os adolescentes em questão mais pesarosos porque se sentiram sozinhos. Entretanto, 12 outros adolescentes não vivenciaram quaisquer alterações em seus relacionamentos, alegando terem tido o cuidado de fazer com que seu problema pessoal não atingisse os demais.

Não me sentia muito a mesma, mas teria que ser porque a pessoas não têm culpa também. Então, não é porque ele faleceu que a gente vai tratar as pessoas mal (menina, 15 anos cujo pai foi assassinado)

\section{O Adolescente Enlutado e Expressão Emocional}

Fatores que dificultam o compartilhamento da perda: 20 dos 25 adolescentes pesquisados reconheceram suas dificuldades de compartilhar suas perdas e de expressar seus sentimentos e emoções. Eles atribuem esse fato a uma conjugação de fatores individuais, familiares e ambientais, como se vê na Tabela 1.

Esses jovens, geralmente se resguardam e aparentam ser auto-suficientes para evitar tocar em conteúdos doloridos ou serem ridicularizados. Eles pensam que ninguém seria capaz de compreendê-los em seus dramas. Só eles mesmos para compreender a dimensão de afetos por eles vivenciados em decorrência da perda.

Não comento nada com ninguém... Porque ninguém vai dar jeito no que eu sinto. Ninguém vai trazer o meu pai de volta. Então eu acho que... fica só para mim. Eu não comento com ninguém, uns podem... até mesmo debochar ou falar alguma piadinha com relação a isso. Ou não ligar, assim ...saber do que eu sinto não tem importância para eles. Ah, por exemplo: 'eu tenho meu pai, você não tem, problema é seu'. Eu já comentei com algumas amigas, mas assim, digamos, no passado, né. E elas não deram muito valor no que eu sentia e no que eu falei. Não ligaram muito e não me deram atenção. Então eu me senti muito mal. E a partir deste momento eu decidi que não comentaria com ninguém (menina, 17 anos)

Tabela 1

Fatores que Dificultam o Compartilhamento da Perda segundo os Adolescentes Entrevistados

\begin{tabular}{|c|c|c|}
\hline Individuais & Familiares & Ambientais \\
\hline $\begin{array}{l}\text { — sentimento de não ser compreendido } \\
\text { em seus sentimentos e emoções. } \\
\text { — considerar a perda como assunto pri- } \\
\text { vado, razão pela qual supostamente nin- } \\
\text { guém compreenderia, não sendo justo } \\
\text { preocupar outrem cabendo, portanto, a si } \\
\text { próprio "livrar-se" de seu sofrimento. } \\
\text { — (pseudo) auto-suficiência: se bastar a } \\
\text { si próprio para se "livrar" do sofrimento. } \\
\text { — dificuldade de se expor e comparti- } \\
\text { lhar sentimentos. } \\
\text { — evitar lembrar a perda para não sofrer. } \\
\text { — chorar quando tenta verbalizar seu pe- } \\
\text { sar. } \\
\text { — dificuldade de se enturmar e fazer } \\
\text { amigos. } \\
\text { - dificuldade de se aprofundar nos sen- }\end{array}$ & $\begin{array}{l}\text { — família pouco afetiva e fechada } \\
\text { e incapaz de compartilhar a perda. } \\
\text { — família intolerante com o luto } \\
\text { do adolescente. } \\
\text { — proibição de falar ou de mani- } \\
\text { festar sentimentos e emoções so- } \\
\text { bre a perda para não magoar as de- } \\
\text { mais. } \\
\text { — evitar preocupar mais a família. } \\
\text { — receio de não ser acolhido em } \\
\text { seu pesar. } \\
\text { — falta de oportunidades de com- } \\
\text { partilhar sentimentos. } \\
\text { — dificuldade de falar sobre a } \\
\text { ocorrência de doença na família } \\
\text { devido a pressão familiar que quer }\end{array}$ & $\begin{array}{l}\text { — ambiente pouco responsivo ou } \\
\text { mesmo hostil ao pesar do ado- } \\
\text { lescente. } \\
\text { — professores e colegas pouco } \\
\text { afetivos/falta de intimidade com } \\
\text { eles/ninguém pergunta/ as pes- } \\
\text { soas não são autênticas. } \\
\text { — ambiente não acolhedor, ofe- } \\
\text { recendo riscos de ridicularização. } \\
\text { — percepção do ambiente como } \\
\text { preconceituosos, (nos casos em } \\
\text { que a perda resulta de causa que } \\
\text { tendem a ser socialmente mora- } \\
\text { lizadas, como AIDS e assassina- } \\
\text { to envolvendo o mundo das dro- } \\
\text { gas). }\end{array}$ \\
\hline
\end{tabular}
timentos quando tenta compartilhar com outrem. 
Entretanto, verificamos que perdas resultantes de assassinato, principalmente as que também envolvem o consumo de drogas, bem como aquelas que envolvem suicídio e AIDS, segundo os depoimentos de quatro adolescentes, foram as mais difíceis de serem expressas e compartilhadas, quer na família quer fora dela.

Meus colegas... não gosto de comentar muito não... Porque eu acho que teria preconceito. Vamos supor: só porque meu tio morreu, poderiam pensar que também eu posso pegar AIDS... nunca cheguei a falar com nenhum dos professores. (menino, 13 anos)

Os sobreviventes dessas perdas se sentiram muito expostos à curiosidade e comentários das pessoas, prejudicando sua readaptação à escola. Em face dessa situação, alguns adolescentes disseram que se sentiam muito abalados e visados a ponto de uma delas ter de largar a escola por um ano até que a situação se esfriasse. Em outros dois casos os adolescentes optaram por se fechar, evitar as pessoas, e desconversar sempre que alguém fazia perguntas, numa atitude defensiva, por não saberem explicar claramente os meandros que levaram à perda do parente por uma causa tão reprovada socialmente. Uma outra lamentou o fato de os colegas se afastarem sempre que tentava conversar a respeito do irmão assassinado.

...nem tudo a gente pode colocar no prato pra elas (as colegas) porque às vezes você vai pôr tudo e elas ficam meio cismadas com você, pensam que a gente vai faze alguma coisa, sei lá, a gente tem o pressentimento que elas olham a gente de outra maneira tipo assim, a gente às vezes vai contar pras pessoas e elas ficam meio estranhas assim, como se não quisessem que a gente contasse ou até mesmo assim ficar junto deles... parecem evitar a gente. Depois do que elas ouviram, dá impressão que elas tentam evitar a gente o máximo possível. (menina, 18 anos, cujo irmão envolvido com drogas foi assassinado)

Todavia, o caso de C. (17 anos), que perdeu um primo por suicídio, afigura-se muito dramático quando se atenta à angústia dela quando questiona sobre o que levara o primo a se matar. Essa angústia acabou adquirindo intensidade cada vez maior em virtude de informações desencontradas, rumores sobre o envolvimento de um tio nessa perda e por não ter sido levada a sério pelos familiares quando insistia em suas perguntas e pelo receio de um drama familiar. Assim sendo, não teve outra saída senão sofrer em silêncio. Eu procuro não deixar saber qual é o motivo que estou tremendo, procuro não falar, se falar...E Eu não comento mais com ninguém, disse.

Psicologia: Reflexão e Crítica, 2003, 16(3), pp. 577-589

\section{Discussão}

A força dos vínculos estabelecidos pelos adolescentes com a pessoa falecida nos é sugerida pelas próprias reações à quebra desses vínculos. Os depoimentos sugerem que esse desligamento causou, na maioria dos casos, uma intensa desorientação. É como se o mundo desabasse, como se nada, agora, com a ausência do ente querido, fizesse mais sentido. Ao mesmo tempo esses relatos trazem à tona frustrações pela privação de gratificações fornecidas anteriormente pelos falecidos no desempenho de diferentes papéis em relação a esses jovens, colocando em relevo o impacto das perdas secundárias, especialmente as de natureza psicossocial.

Embora algumas qualidades atribuídas às pessoas perdidas possam conter o viés da distorção retrospectiva, particularmente a idealização, muito freqüente no discurso da pessoa enlutada (Parkes, 1998), os depoimentos nos levam a pensar que a maioria dos adolescentes mantinha com as pessoas falecidas vínculos fortes, o que justifica o desejo intenso desses jovens de reaver essas pessoas. À medida que fomos coletando os depoimentos, foram se esboçando alguns traços do perfil e da dinâmica familiar na qual as perdas aconteceram. Em torno da família, acentuou-se a ausência da figura paterna e conflitos diversos, sendo que na maioria dos casos o apego às pessoas que vieram a falecer compensava em parte as necessidades afetivas negligenciadas na família nuclear. Segundo Calvin e Smith (1986), o senso de perda do sobrevivente está diretamente associado ao conjunto de funções fornecidas pela pessoa perdida, sua importância e exclusividade. Em outras palavras, é como sintetiza Marris (1993) quando afirma que $A$ intensidade do pesar está mais relacionada com a intensidade do envolvimento do que com a do amor. (p. 33)

As informações disponíveis não nos permitem avaliar precisamente o quanto o conhecimento tardio da perda e a tentativa de ocultar o ocorrido afetaram a expressão do luto pelos adolescentes. Porém, certamente a chegada tardia da informação impediu que esses adolescentes participassem plenamente dos acontecimentos da perda, dificultando o processo de reconhecimento da realidade dessa perda e a socialização do pesar. Essas situações são suscetíveis de comprometer o processo normal do luto. Como já se tratou neste trabalho (Aberastury, 1984; Bowlby, 1993), sonegar informações da perda às crianças faz parte de uma tendência ancorada no senso comum, segundo a qual a criança não tem capacidade de sentir e compreender a perda, ou que expô-la aos acontecimentos da morte poderia traumatizá-la. No entanto, pode-se afirmar que essas tendências revelam antes a dificuldade 
dos próprios adultos em enfrentar a perda. Segundo Bowlby (1993), a informação distorcida fornecida à criança pode levar à ausência de luto consciente, condição essa passível de complicar a integração da experiência da perda, imprescindível para a acomodação do luto. Como mostram os casos de suicídio e os de homicídio, notadamente aqueles com envolvimento de drogas, o emaranhado desencontros de informações, a dificuldade da família em compartilhar os acontecimentos da perda, o receio dos sobreviventes em se expor ou a impossibilidade de explicar para si mesmos e para os outros os detalhes sobre a morte do ente querido, foram aspectos que contribuíram tanto para a distorção da informação sobre a perda, quanto para deixar os sobreviventes sem o devido suporte social. Conseqüentemente, esta situação trouxe dificuldade para a elaboração da perda.

As reações imediatas explicitadas pelos adolescentes compõem o entorpecimento ou choque, quadro clínico subseqüente ao momento em que a pessoa recebe a notícia da perda, podendo prolongar-se por horas ou semanas. Essas respostas podem ser desestruturantes, principalmente quando a perda é repentina.

Dependendo do vínculo estabelecido com a pessoa falecida e da personalidade do enlutado, o mundo deste pode ruir, daí o pavor, a desorientação, o choque e o desespero. Embora peculiar de indivíduo para indivíduo, o entorpecimento apresenta como característica comum um nível de tensão elevada (Bowlby, 1993). Alguns autores como Rando (1993), identificam esta fase como fase de evitação, combinando uma complexidade de sentimentos e emoções extremados como raiva, dor intensa, tristeza, histeria, protesto, desejo intenso de evitar a realidade perda de controle, entre outras perturbações. O descrédito e a necessidade de saber o porquê da perda são reações comuns nessa fase, bem como a tendência de negá-la. Para Rando (1993), essa tendência tem uma função terapêutica porque é como se fosse uma anestesia que possibilita ao enlutado vivenciar a dor da perda de forma paulatina, isto é, menos desestruturante.

No tocante aos seis entrevistados que somente na adolescência ressentiram-se das perdas sofridas na infância sua experiência revela lutos adiados que ressurgiram nessa nova fase de desenvolvimento. Ainda que o adiamento da perda seja um dos preditores do luto patológico (Parkes, 1998; Rando, 1993), não nos parece ser esse o caso. Parece ter pesado, aqui, a fraqueza dos vínculos estabelecidos com os falecidos, uma vez que o luto só ocorre em resposta a um vínculo que se desfez. Por outro lado, a pouca idade desses jovens quando das perdas, pode ter dificultado o processamento cognitivo da perda. Como alerta Mahon (1999), na medida em que se desenvolve, a criança tem necessidade de integrar a experiência da perda através do reenlutamento. Por outro lado, o luto das perdas passadas pode ser atualizado em conseqüência de novas perdas.

Quanto às reações de raiva e hostilidade, expressas ora indiscriminadamente, ora direcionadas, aparecem com maior acuidade nas perdas por homicídio. Elas se justificam por evocar nos sobreviventes a impunidade dos assassinos, fazendo com que esses sobreviventes se sintam vitimizados e vulneráveis. Por outro lado, por serem repentinas, essas perdas situam-se entre as potencialmente mais perturbadoras e difíceis de serem elaboradas (Abrams, 1994; Parkes, 1998).

O fato de a metade dos adolescentes pesquisados, após a perda sofrida, passarem a se preocupar com a morte e o morrer, parece responder a uma situação em que a perda do outro evoca a própria finitude e, sobretudo, a vulnerabilidade pessoal, condições essas que correntemente tendem a ser eclipsadas pelo mito da onipotência usualmente encarnado pelo jovem na sua adolescência. Por outro lado, a análise desses casos nos permite pensar que o senso de vulnerabilidade em questão é mais intenso porquanto as causas das perdas são repentinas e com intervenção de eventos externos (acidente de viação, assassinato) aterrorizantes porque brutais e fora do controle dos adolescentes. Essas formas de tensão psicossocial questionam o senso do eu avivando e trazendo à tona a angústia básica do ser humano que é a preocupação com a própria finitude (Kastenbaum \& Ainsenberg, 1983). Também não se pode perder de vista que os medos relatados pelos jovens podem ser potencializados pelas ansiedades inerentes à adolescência, a saber, a construção da própria identidade (Aberastury \& Knobel, 1981). Portanto, quando alguns desses adolescentes dizem que pesquisaram ou refletiram a respeito da morte a ponto de terem superado o medo da morte, isso nos sugere uma atitude defensiva a favor do senso de controle de suas vidas, qual uma tentativa de domar a morte que agora, no contexto da perda, tornou-se um fato ameaçador à própria existência. Observa-se que a perda levou esses adolescentes a fazer perguntas sobre a vida e morte, de cujas repostas se esboçaram novas atitudes diante desses fenômenos, num processo de ressignificação de seu viver, que em alguns casos se assemelhou mais a uma fruição imediata do presente, o que é visto por Costa (1991) como um sintoma da cultura da violência em que o futuro é negado ou representado como uma ameaça de aniquilamento ou distorção (p. 130).

A perda foi também percebida como ausência, sendo portanto vivenciada como falta que suscita saudade. À privação de gratificações fornecidas no passado pelo falecido, associaram-se a tristeza, o choro e a raiva, que são na verdade reações a perdas secundárias (Rando, 1993). 
A manifestação episódica dessas emoções foi conceituada por Rando com o nome sugestivo de Subsequent Temporary Upsurges of Grief (ou STUG reactions), isto é, reativação subseqüente e temporária do pesar, para caracterizar períodos breves e temporários de pesar agudo relativo a uma perda significativa. Essas respostas são precipitadas por eventos que reafirmam a ausência do ente querido. Ainda que a maioria dessas respostas faça parte do luto normal, elas podem indicar a presença de um luto com aspectos não resolvidos da perda ou de resposta disfuncional a esta (Rando, 1993). Alguns adolescentes sentiram um misto de saudade e intensa frustração por terem perdido um pai que não chegaram conhecer na infância, perdendo assim a oportunidade de algum dia vir a conhecê-lo. Esta situação configurou pesar por aquilo que nunca tiveram e agora nunca terão (Calvin \& Smith, 1986, p. 227). Essa constelação de reações deve ser considerada como lutos devidos a perdas secundárias, nos termos de Rando (1993), que se desdobram em lutos duradouros que demandam maior esforço de elaboração. As perdas secundárias tendem, pois, a complicar a adaptação a perdas primárias (Mahon, 1999). Quanto mais importantes as mudanças impostas pela perda inicial, maior a magnitude e extensão das perdas secundárias, pela imposição de novas e nem sempre fáceis adaptações. Os adolescentes que tiveram que mudar de casa em virtude da perda não se adaptaram aos novos ambientes, pois à perda inicial se agregaram a perda do aconchego do espaço habitual, da escola, da interação com colegas de sempre e pessoas próximas. Esta situação aumentou o desconforto desses jovens, além de minimizar as possibilidades de suporte social.

Algumas experiências de perda foram vivenciadas como luto antecipatório que teve como objeto parentes acometidos por doença terminal. Nesse tipo de luto o indivíduo sofre pela falta de convivência com o ente querido, aliada à experiência de testemunhar a deterioração física deste (Abrams, 1994; Kovács, 1992). Para Abrams (1994), esta espécie de morte-em-vida, isto é, quando alguém morre em um sentido e continua vivo em outro, pode implicar em falta de clareza sobre o que se perde, situação essa passível de tornar o luto mais difícil. Em um outro extremo, alguns adolescentes só tardiamente, na adolescência e diante de perdas recentes, ressentiramse das perdas sofridas na infância, o que caracteriza uma situação segundo a qual lutos adiados ou mal elaborados podem ser desencadeados por perdas recentes, como muito provavelmente foi o caso desses jovens.

Tanto a perda quanto o luto atingiram o equilíbrio e funcionamento familiar, desencadeando ou acirrando conflitos intrafamiliares, o que é esperado como conseqüência Psicologia: Reflexão e Crítica, 2003, 16(3), pp. 577-589 da frustração do desejo intenso de reaver o objeto perdido e da necessidade de expressão de fortes emoções que freqüentemente tomam a forma de revoltas e acusações. Estas vivências parecem estar aliadas a situações como: padrão afetivo familiar pouco responsivo às necessidades dos adolescentes enlutados, parentes também enlutados e, em alguns casos, dependentes da ajuda do adolescente, em detrimento das necessidades deste último. Se de um lado essa situação se constituiu em acréscimo de stress para o jovem enlutado, por outro lado tornou a família, enquanto fonte de suporte, pouco eficaz ou mesmo nula, confirmando um achado recorrente e largamente citado na literatura (Bowlby, 1993; Bromberg, 1994; Gordon, 1986; Harris, 1991; Pincus, 1989; Rosenthal, 1986).

Como pudemos verificar nos depoimentos, na escola o déficit de atenção e concentração aparece como o maior problema enfrentado pela metade dos entrevistados. Isso parece ocorrer devido principalmente à ansiedade, quadro conhecido na literatura sobre luto (Bromberg, 1994; Dyregrov, 1992; Harris, 1991). A comunidade escolar, na percepção dos adolescentes, mostrou-se pouco eficaz e, às vezes, ausente como suporte para seu luto, ainda que a maioria deles admitisse sua postura defensiva quanto a se expor no contexto de um ambiente escolar considerado por eles como pouco responsivo em termos afetivos. Embora a maioria desses jovens tenha identificado algum apoio de colegas e professores, esse apoio parece ter tomado sobretudo a forma de ajuda prática e de encorajamento, não oferecendo suficiente suporte às necessidades emocionais decorrentes da perda.

Percebendo-se pouco compreendidos e acolhidos em seu luto e sentindo-se indispostos com todo o mundo, alguns adolescentes se desentenderam com os colegas. Conseqüentemente, sentiram-se abandonados pelos amigos e grupos habituais ou simplesmente não conseguiram se integrar neles, ficando a sós com o próprio pesar. Entretanto, metade dos entrevistados, possivelmente numa atitude defensiva de se sentir sob controle, afirmaram que a perda não afetou seus relacionamentos porque souberam lidar com ela.

Como se vê na Tabela 1, fica clara a existência de uma conjunção dinâmica de fatores de ordem individual, familiar e escolar por trás das dificuldades dos adolescentes pesquisados em lidar com a perda e conseguir suporte. Os pesquisados utilizam expressões que sugerem um comportamento defensivo e apesar de terem a consciência deste fato, culpam os outros por isso. Para esses jovens, franquear seus dramas significa arriscar-se a serem minimizados ou ignorados em sua dor, uma vez que, para eles, ninguém, a não ser eles próprios, compreende sua dor. Considere-se também que o consolo de outrem pode 
aparecer, a seus olhos, como a confirmação da perda, uma realidade que ele ainda é incapaz de encarar.

As perdas por suicídio e por homicídio com envolvimento de consumo de drogas, bem como as resultantes de AIDS, comportam uma dificuldade a mais para serem compartilhadas, pois além de freqüentemente estarem cercadas de informações obscuras, trazem dúvidas a respeito da integridade moral das próprias vítimas e, inclusive, do sobreviventes, que acabam sendo alvo de atitudes preconceituosas e moralistas. Por outro lado, ao pesar da perda se adiciona o esforço de se esconder, de não revelar a perda, de guardá-la só para si e a subseqüente ansiedade de ser descoberto ou pressionado a falar dela. Essas situações acabam se juntando ao estresse resultante da perda, potencializando-o. A dificuldade de expressar e compartilhar o pesar, explicitada por esses adolescentes, se afigura como uma das muitas variações do pesar não autorizado, conceito cunhado por Kenneth Doka e posteriormente ampliado por Corr (1998-1999), como já expusemos anteriormente.

\section{Considerações Finais}

O estudo desvela pela primeira vez as reações de um grupo de jovens estudantes brasileiros e confirma, em suas linhas gerais, os achados já consagrados na literatura sobre morte e luto. As vivências expressas nos depoimentos refletem apenas parte de um todo complexo cujos efeitos atingiram os adolescentes em várias dimensões de suas vidas. Mais que mostrar a vulnerabilidade dos pesquisados com relação à perda de entes queridos, o estudo nos leva pensar o quanto as instituições sociais, especialmente a família e a escola, têm que saber lidar com situações portadoras de fortes emoções, particularmente com o luto. $\mathrm{O}$ padrão afetivo dominante nesses espaços freqüentemente não favorece a resolução de situações decorrentes do luto, inviabilizando a expressão de afetos e respectiva escuta, processos esses da maior importância, ainda que por si sós não garantam um luto sem complicações.

$\mathrm{Na}$ escola, como pudemos verificar neste estudo, o luto tem implicações no processo de ensino-aprendizagem, devendo ser considerado como uma questão com correlatos pedagógicos, merecedora de grande atenção. Coloca-se questão: como a escola poderia lidar com a demanda dos alunos enlutados? A resposta a essa questão leva ao centro do debate a sempre atual discussão sobre o lugar da afetividade nos processos de escolarização.Como pensar ou resgatar uma escola responsiva às necessidades de seus usuários? Seja como for, entendemos ser de grande importância que a escola, a par de suas preocupações em transmitir conhecimento, também esteja atenta às necessidades emocionais de seus alunos, uma vez que a cognição e as emoções são inseparáveis no desenvolvimento psicológico. Deste modo, é importante que a escola seja sensibilizada para a questão do luto, principalmente através da mediação de seus agentes educacionais. Para tanto, tornase fundamental buscar parcerias com centros especializados que já existem localmente, para ajuda profissional em termos de treinamento e assessoria a educadores, bem como encaminhamento de alunos e suas famílias, quando se fizer necessário.

\section{Referências}

Aberastury, A. (1984). A percepção da morte nas crianças (M. N. Folberg, Trad.). Em A. Aberastury \& cols. (Org.), A percepcão da morte na criança e outros escritos (pp. 128-139). Porto Alegre: Artes Médicas. (Original publicado em 1978)

Aberastury, A. \& Knobel, M. (1981). Adolescencia normal: Um enfoque psicanalitico (S. M. G. Ballve, Trad.). Porto Alegre: Artes Médicas. (Original publicado em 1970)

Abrams, R. (1994). When parents die. London: New Holland.

American Psychiatric Association (1989). Manual de diagnóstico e estatistico de distuŕrbio. mentais DSM-III-R. (L. H. S. Barbosa, Trad.). São Paulo: Manole. (Original publicado em 1987)

Ariès, P. (1977). Historia da morte no ocidente (P. V. Siqueira, Trad.). Rio de Janeiro: Francisco Alves. (Original publicado em 1975)

Ariès, P. (1982). O Homem diante da morte (L. Ribeiro, Trad.). Rio de Janeiro: Francisco Alves. (Original publicado em 1977)

Bardin, L. (1977). Análise de conteńdo (L. A. Reto \& A. Pinheiro, Trad.). Lisboa: Edições 70. (Original publicado em 1977)

Bluebond-Langner, M. (1977). Meanings of death to children. Em H. Feifel (Org.), The meanings of death (pp. 47-66). New York: McGraw-Hill.

Bowlby, J. (1982). Formagãa e rompimento de lagos afetivos (A. Cabral, Trad.). São Paulo: Martins Fontes. (Original publicado em 1972)

Bowlby, J. (1993). Separação: Angústia e raiva. Em Apego e perda: Vol. 2 (L. H. B. Hegenberg \& M. Hegenberg, Trad.). São Paulo: Martins Fontes. (Original publicado em 1973)

Bromberg, M. H. F. P. (1994). A psicoterapia em situacōes de perda e luto. Campinas: Editorial Psi II.

Calvin, S. \& Smith, I. M. (1986). Counseling adolescents in death related situations. Em Corr, C. A. \& McNeil, J. N. (Orgs.), Adolescent and death (pp. 215-230). New York: Springer:

Corr, C. A. (1998/1999). Enhancing the concept of disenfranchised grief. Omega, $38,1-20$.

Costa, J. F. (1991). Narcisismo em tempos sombrios. Em H. R. Fernandes (Org.), Tempos do desejo: Sociologia e psicanálise (pp. 109-136). São Paulo: Brasiliense.

De Mico, S. (1995). Young adults reactions to death in literature and life adolescent. Adolescence, 30, 117-185.

Dyregrov, A. (1992). Grief in cbildren. London: Jessica Kingsley.

Erikson, E. H. (1971). Infância e sociedade (G. Amado, Trad.). Rio de Janeiro: Zahar. (Original publicado em 1950)

Fleming, S. J. \& Adolf, R. A. (1986). Helping adolescents: Needs and responses. Em A. Corr \& J. N. McNeil (Orgs.), Adolescent and death (pp. 97-118). New York: Springer

Gordon, A. K. (1986). The tattered cloak of immortality. Em C. A. Corr \& J. N. McNeil (Orgs.), Adolescent and death (pp. 16-31). New York: Springer. 
Harris, E. S. (1991). Adolescent bereavement following the death of a parent: A exploratory study. Child Psychiatry and Human Development, 21, 267-281.

Kane, B. (1979). Children's concepts of death. Journal of Genetic Psychology, 134 141-153.

Kastenbaum, R. (1986). Death in the world of adolescence. Em C. A. Corr \& J. N. McNeil (Orgs.), Adolescent and death (pp. 4-15). New York: Springet

Kastenbaum, R. \& Ainsenberg, R. (1983). Psicologia da morte (A. P. Lessa, Trad). São Paulo: EDUSP. (Original publicado em 1976)

Koocher, G. P. (1973). Childhood, death, and cognitive development. Psycholog, 9,369-375

Kovács, M. J. (1992). Profissionais da saúde diante da morte. Em M. J. Kovác (Org.), Morte e desenvolvimento humano (pp. 46-64). São Paulo: Casa do Psicólogo.

Mahon, M. M. (1999). Secondary losses in bereaved children when both parents have died. A case study. Omeoga, 39, 297-314.

Mahon, M. M., Goldberg, R. L. \& Washington, S. K. (1999). Discussing death in the classroom: Believes and experiences of educators and education students. Omega, 39, 99-121.

Marris, P. (1993). Loss and change. New York: Routledge.

McNeil, J. N. (1986). Talking about death: Adolescents, parents and peers. Em C. A. Corr \& N. J. McNeil (Orgs.), Adolescence and death (pp. 185-201). New York: Springer.

Middleton, W., Raphael, B., Martinek. N. \& Misso, V. (1993). Pathological grief reactions. Em M. S. Stroebe, W. Stroebe \& R. O. Hansson (Orgs.), Handbook of bereavement: Theory, research, and intervention (pp. 44-61). Cambridge:

Nagy, M. (1948). The child's theories concerning death. The Journal of Genetic Psychology, 73, 3-27.
Parkes, C. M. (1993). Psychiatric problems following bereavement by murder or manslaughter. British Journal of Psychiatry, 162, 49-54.

Parkes, C. M. (1998). Luto: Estudo sobre aperda na vida adulta. (M. H. F. Bromberg, Trad.). São Paulo: Summus Editorial. (Original publicado em 1996)

Pincus, L. (1989). A familia e a morte: Como enfrentar o luto (F. Murad, Trad). Rio de Janeiro: Paz e Terra. (Original publicado em 1974)

Rando, T. A. (1993). Treatment of complicated mourning. Illinois: Research Press. Rando, T. A. (1993). Treatment of complicated mourning. Illinois: Research Press.
Rosenthal, N. R. (1986). Death education: Developing a course of study for Rosenthal, N. R. (1986). Death education: Developing a course of study for
adolescents. Em C. A. Corr \& J. N. McNeil (Orgs.), Adolescent and death (pp 202-214). New York: Springer.

Rowling, L. (1995). The disenfranchised grief of teachers. Omega, 31, 317-329. Schacter, S. (1991/1992). Adolescent experience with the death of a peer. Omega, $24,1-11$.

Skalar, F. \& Hartley, S. F. (1990). Close friends as survivors: Bereavement patterns in a "hidden" population. Omega, 21, 103-112.

Stroebe, M. (1992-1993). Coping with bereavement: A review of grief work hypothesis. Omega, 26, $19-42$.

Torres, W. C. (1979). O conceito de morte na criança. Arquivos Brasileiros de Psicologia, $31,9-34$. Aceite Final: 16/05/2003

Sobre os autores

Basílio Domingos é Psicólogo, Mestre em Psicologia pela Universidade de São Paulo. Atualmente é bolsista da FAPESP no Programa de Doutorado em Psicologia Escolar e do Desenvolvimento Humano do Instituto de Psicologia da Universidade de São Paulo.

Maria Regina Maluf é Psicóloga e Doutora em Psicologia pela Universidade de Louvain (Bélgica). Professora associada do Instituto de Psicologia da Universidade de São Paulo e Professora titular da Pontifícia Universidade Católica de São Paulo. 